\title{
EVIDENCE AND STORIES ABOUT EVIDENCE: STANFORD PRISON EXPERIMENT UNDER CRITICISM
}

POPULAR SCIENCE ARTICLE

\author{
Kamil Izydorczak* \\ Mała Psychologia \\ www.mala-psychologia.eu \\ Wroclaw, Poland \\ k. izydorczak@malapsychologia.eu
}

\author{
Agata Wicher \\ Mała Psychologia \\ www.mala-psychologia.eu \\ Cracow, Poland \\ a.wicher@malapsychologia.eu
}

September 2, 2019

\begin{abstract}
The Stanford Prison Experiment conducted by Philip G. Zimbardo is probably the most recognizable study in the area of social psychology. The summer of 2018 proved to be exceptionally unfavourable to this scientific endeavour. The experiment was showered with strong criticisms to the extent that some voices were raised to withdraw the research from psychology textbooks; the study was no longer described as 'shocking', but rather as a 'sham' or 'lie'. At a closer look, it turns out that the whole criticism can be traced back to one source article which contains unevenly distributed arguments. Some of them are relevant and new, but others can be described as hyperbolas, simplifications and repetitions of frequent allegations. An attentive and critical look at Zimbardo's Stanford Prison Experiment and arguments against it helps to develop a more complex, but also more interesting perspective. It could serve as an example of a fierce, fascinating fight for a politically and socially important cause. In this fight, both sides remain faithful to their stance rather than to the facts. It is also a story about the problem of reporting science in a sensational way.
\end{abstract}

Keywords Zimbardo $\cdot$ Stanford Prison Experiment $\cdot$ criticism $\cdot$ Ben Blum $\cdot$ social psychology $\cdot$ scientific scepticism

\section{THE FALL OF THE KING}

Every amateur of scientific psychology must have heard about the Stanford Prison Experiment (SPE) conducted by professor Philip Zimbardo. The study, which undoubtedly stimulates imagination, has been discussed in textbooks, referred to by feature writers, commented in popular press. Currently, it is being described as a 'lie' or a 'sham', voices have been raised to 'change the story' and 'get it out of textbooks'. Criticisms are not only to be found on blogs or Twitter, but it is also on its way to scientific journals. At first glance, it seems that the emperor has no clothes and only the most avid followers of the falling authority will persist in defending him. In fact, the issue is more complicated.

\section{I will tell you honestly and openly what we know, what we don't know and what I personally think about Zimbardo v. Scathing Criticism (Rest of the World, 2018)}

Firstly, let's take a look at the scale of criticism of the SPE. So many of us may have already come across it in various

${ }^{*}$ First author prepared the manuscript, second author translated the manuscript from Polish. Correspondence concerning this article should be addressed to Kamil Izydorczak 
sources that it is easy to be misled. When we hear some piece of information repeatedly, it appears to be more certain than if we have heard it only once.

There is a rational explanation to it - the more people independently claim that something happened, the more we can trust this information. However, when one person gives an account of something and many people follow, it can be hardly said that the claim is hence more credible. The whole story is only as true as the message conveyed by the first person, but it appears to be a common view when multiplied (Weaver, Garcia, Schwarz and Miller, 2007).

This is the case of the ubiquitous criticism of the SPE - such texts, although numerous, are usually commentaries and interpretations based on two sources - an article by Ben Blum and a book by Thibault Le Texier Histoire d'un mensonge [History of a Lie]. In fact, the main source is just the Blum's text. For now, Thibault Le Texier's book is discussed and commented rather than read as it is only available in French (Le Texier, 2018). The criticism in English mostly consists of duplication, interpretation and commenting of one source account. Let us examine it in more detail.

\section{BLUM AND THE CASE OF ZIMBARDO}

Ben Blum, who holds a PhD in computer science, published his first book Ranger Games in September 2017 (Blum, 2017). It is the story of his cousin, Alex Blum, a former member of U.S. Army Rangers who took part in a bank robbery led by his superior officer. The Blum family was deeply convinced of Alex's innocence as he had been an exemplary young man, and thus they asked professor Zimbardo for help in the legal battle that ensued. He was supposed to testify about the power of social situation and the prevalent influence of long-term training of submission towards one's military supervisor.

Thanks to his involvement in Alex story, Philip Zimbardo became a hero for the Blum family, whereas Ben Blum became interested in the professor's research. His interest developed in an unexpected direction: after extensive investigation and a few plot twists in his cousin's story (for instance, Alex confessed that he had been more aware of his deeds than he had previously claimed), Ben Blum proclaimed the professor's most famous experiment as a sham, and its conclusions as a socially destructive, moral justification of crimes.

According to Blum, the prison experiment gives us an easy excuse: 'it's not me, it's the situation', and thus it liberates us from the need for profound repentance and accepting responsibility for our actions. Blum presented these conclusions in his article entitled „A lifespan of a lie” (Blum, 2018).

\section{Main theses}

In his article, the author advances several strong theses:

1. The extreme behaviours of the participants - which served as iconic examples - were faked,

2. Zimbardo and his team incited aggressive behaviour among the guards on purpose,

3. Zimbardo tried to silence his critics,

4. Zimbardo imposed morally misleading public commentary about the experiment,

5. The participants did not know how to quit the experiment.

The text ends with the conclusion: 'it's a lie'. Not an 'exaggeration', 'inaccuracy', or 'manipulation', but a 'lie'. Even in the era of replication crisis in psychology, such verdicts are rarely passed. So far, the research of Diederik Stapel has been labelled as a 'lie' or a sham (cf. e.g. Bhattacharjee, 2013; Klebaniuk, 2012), but in that case the author simply made up his research results. Therefore, it appears that Zimbardo is attacked with very strong allegations and it is worthwhile examining if the provided evidence is as powerful as the accusing theses.

\section{WHICH PART OF THE SPE IS A LIE?}

\section{The participants were faking}

Acting is an important thread in Blum's criticism. He claims to have found evidence that the behaviour of the experiment participants was not an expression of their authentic emotions or attitudes, but merely a show, consciously acted out. The greatest breakthrough is supposed to be the case of Douglas Gordi, the notorious prisoner no. 8612. His hysterical nervous breakdown went down in history as a striking illustration of one's mental suffering in a total institution that drives people to insanity even if it is only staged. 
According to the author, however, it turned out that Gordi had been bluffing. He faked the nervous breakdown because he did not have access to books he needed for studying for an exam. He did not know any other way to opt out of the experiment (I will come back to this matter later), so he chose to simulate a bad mental condition. The fact that he had attended drama classes supposedly adds more credibility to this story. What kind of evidence does Blum provide in this case? A statement of Douglas Gordi (Blum, 2018). And on what premises Gordi's behaviour had been previously judged as authentic? A statement of Douglas Gordi.

The problem is that we are trying to solve the issue of mental states, thoughts and motivations, which by definition can only be fully known to the person who experiences them. If somebody issues contradictory statements on a given subject, how can we know when they are telling the truth, and when they are lying? We could present legitimate psychological arguments supporting the credibility of either of these statements. Moreover, in the wake of discoveries of cognitive psychology, it is also possible to be in a state where we are not able to honestly report the motivation of our actions or faithfully recall events in which we participated (e.g. Lilienfeld et al., 2011, Chapter 3).

When somebody makes a statement about one's own mental states which differs from their previous claim, it should sow suspicion. However, it is hardly convincing that such contradictory statements of one person provide irrefutable evidence clarifying what is true, and what is not.

Another important SPE figure accused of acting is David Eschelman. He was the infamous, most sadistic of the guards, nicknamed 'Hellman' by the prisoners and 'John Wayne' by the SPE researchers because of his Southern accent and a tough guy pose. According to Blum, he was only pretending, just like Gordi. Namely, he faked the Southern accent (he had never even been to the South of the U.S.) and modelled his whole personality on the prison superintendent from the film Cold Hand Luke. Eshelman's statement also serves as evidence here. This time though, there is no doubt that his claim is credible. Eshelman, unlike Gordi, never changed his version - he has been repeating it at least since 2004 (cf. source).

In this case, Blum does not provide any new evidence, but only complements his argumentation with commonly known facts. Albeit, it is hard to concede that the results of the situation research are less credible only because David Eshelman faked somebody's accent or other behaviour. After all, 'Hellman' did not 'fake' ordering the prisoners to act out copulation - he really did give such an order, and the prisoners obeyed. The same case was with other sadistic punishments and orders. Just because he modelled his behaviour on somebody does not undermine the research conclusions. On the contrary - in the original article, the authors claim that people placed in a total institution try to adapt to the conditions, for instance by intensely imitating somebody - be it a friend or a media figure (Zimbardo, Haney, Banks, 1973).

\section{The staff instigated the guards to aggressive behaviours}

The second important element in Blum's criticism is the pressure exerted by Zimbardo and his team on the prison guards that supposedly modified their behaviour, or even constituted its main cause. It is a serious accusation; after all, one of the most shocking threads of the SPE story is the spontaneity of the guards' brutal behaviours. If they did not come up with this aggression by themselves, it means that not the mythical 'situation', but the central instructions turned most of the guards into real villains. Here, the evidence can be found in the research archives of the open-access Stanford library.

Blum and the following SPE critics focus on a 2-minute long fragment of a recording where David Jaffe, a research assistant who played the prison's warden, instructs one of the guards. I listened to this recording several times (also to its full version). One can hear some sort of a reprimand regarding the insufficient involvement of the guard in the role ascribed to him. The strongest words addressed at the guard are: 'The guards have to know that every guard is going to be what we call a tough guard' and 'so far your individual style is a little bit too soft'.

As explained by Zimbardo, the instructions were regarding a situation where the guard left the area where he was supposed to be, he was not helping his colleagues in the ascribed duties, he was indecisive and not sufficiently 'tough' and 'firm'. Irrespective of how we assess the impact and results of this intervention, we face two serious problems here. First, it is impossible to impartially and unequivocally interpret this situation as 'coaching to act aggressively', which is how Blum puts it in one of the interviews. There is an essential difference between instructions encouraging violence and instructions encouraging decisiveness, firmness and engagement. If there is no such difference, then each staff meeting taking place anywhere in the world at the moment can be called a hatred session.

Throughout the years Zimbardo confessed repeatedly that the guards had been instructed to maintain 'law and order', or even control the prisoners using the full range of power and privileges, except for physical violence (it is mentioned e.g. in Quiet Rage: The documentary). I do not see why Jaffe's intervention should be treated as anything other than the 
realisation of the initial guidelines. Of course, such instructions can and should be subject to criticism and discussion. But the question is whether Blum's article really is a watershed; a justification for calling the SPE a 'lie'.

The second problem is the scale of conclusions drawn from one recording. Does it really illustrate the entire relation between the experiment staff and this particular guard? Can we know for sure that such interventions were multiple and that they were the main source of bias also in the other guards' behaviour? No other archival evidence has been provided. Thanks to a diary entry we know that Jaffe intended to make the guards' behaviour more authentic, so that they were more rough and 'tough'. This approach is an open consent to direct intervention in result's variation. Blum's article does not provide detailed description of the interventions, nor does it state how many of them took place.

\section{When we make conclusion about interpersonal relations or a social situation on the basis of their mere fragment, we do not account for the diversity and complexity.}

It is hard to judge if one fragment conveys the entire truth. This illusion is called 'the fallacy of composition' (Kousta, 2017) The arguments might have been as well supported by another scrap of the archived material - for instance, a fragment of a guard's diary, recalled by Zimbardo in the original New York Times Magazine article (Zimbardo, Haney, Banks, 1973). On the fourth day of the experiment, the guard complains about the research staff behaviour who reprimanded him for handcuffing and blindfolding a prisoner. The guard felt offended and answered that he was only doing what was necessary to maintain safety. Could we use this account as a credible argument that the guards were, on the contrary, 'systematically discouraged from aggression'?

\section{Zimbardo tried to prevent criticism of his work and its replication}

Ben Blum mentions an attempt at 'replication' of the SPE by a team of British researchers led by Alexander Haslam and Stephen Reicher and their results whose were drastically different. The replication was supposed to demonstrate that the guards' brutality stemmed mostly from purposeful action of their supervisors and their voluntary involvement for science. Blum mentions Zimbardo's backroom attempts to prevent the publication of the results.

I was outraged when I read this part of the article. Blocking the free, critical and replicable science is a misdeed that could be expected from the dogmatic tyrant and not a distinguished researcher. But Blum leaves something unsaid. The supposed 'replication' was actually a reality show produced by BBC, whereas Zimbardo's criticism consisted first in correspondence with the editorial board of a scientific journal and then a polemic commentary in this journal (Zimbardo, 2006).

Zimbardo explains that initially he was invited as a counsellor in the planned program, but he declined because of ethical reasons. Later on, he published substantive criticism of the idea and his moral reservations in the scientific journal. He also presented his arguments why such study cannot be treated as replication, and its results should not be published in scientific journals. In this context, the situation looks quite different. Instead of a demonic intellectual tyrant secretly intimidating other scientists, he appears as a researcher who acts openly and expresses his criticism based on ethical and factual arguments. It can be described as free scientific activity, even if a lot of ego is involved.

In Blum's text, the BBC experiment is juxtaposed with the original SPE research which creates the impression that the author regards the first one as the correct version of the latter. But as far as Zimbardo's experiment was full of gaps and does not authorise us to draw any serious conclusions on human nature, we should apply the same scale of criticism to the $\mathrm{BBC}$ project. It is hard to defend it as replication since too many elements are different from the original procedure. As a separate experiment, it introduces so many confounding factors that it is difficult to determine what the results mean. Enough said that all participants were aware that their actions being registered and published to anyone who wished to see them - including their close ones and supervisors. It is a factor which strongly modifies one's behaviours, and thus the social situation was completely different than the anonymity, isolation and reinforced de-realisation of the original study.

\section{Zimbardo tried to prevent criticism of his work and its replication}

This accusation seems the most serious from a social point of view. Tomasz Witkowski is right to notice that psychology is one of few areas of science where discoveries can so quickly and easily change the way people think about themselves and thus maybe change their behaviour (Witkowski, 2018). Such power entails great responsibility. According to Blum and many other critics, the SPE is an example of abuse of this power. However, this allegation can only be justified 
if we identify the message of the SPE correctly - after all, one needs to precisely present somebody's view prior to criticising it. Moreover, it would be necessary to demonstrate that due to distortions and defects of the study, its message is essentially incorrect.

Blum states in one of the interviews that 'the experiment implied that evil is lurking in all of us (...) waiting for a situation'. In his article, he writes: What is unique, and uniquely compelling, about Zimbardo's narrative of the Stanford prison experiment is its suggestion that all it takes to make us enthusiastic sadists is a jumpsuit, a billy club, and the green light to dominate our fellow human beings'.

\section{Perhaps the conclusion that 'everybody is evil when forced by the situation' is what most of us takes as the main message of the SPE, but it is hard to find it in the original article.}

Zimbardo's experiment, scientifically speaking, did not regard this subject. It was not about explaining the mystery of evil, but human behaviour in the so-called total 'institutions'. Its conclusions drew only on such situations, not any situations in general.

The conclusions are as follows: if we confine two groups of people with extremely different levels of power and prestige, and reinforce their group identity at the cost of their individual identity, we can expect that the 'stronger' group will expand and abuse their power, while the 'weaker' group will go through various stages of reaction - from rebelling to passivity and lack of solidarity.

The authors of the SPE suggest that these effects are triggered by many various elements of the 'prison' or 'total' situation - e.g. the dynamic, complex relation between the prisoners and guards. The latter group, afraid of the power of the oppressed, try to prevent them from solidarity and 'tighten the screws'. Because of the instinct of revolt, the authorities become even more convinced that they need to be strict, whereas further repressions reinforce hatred and helplessness among the subjects. Jumpsuits and billy clubs definitely played a role here, but they were not crucial.

Now, is the message of Zimbardo's experiment as follows: 'evil is induced by the situation'? Blum and many of the following critics think so. Such conclusion can definitely be found in the public opinion. Zimbardo himself might have contributed to spreading of this conclusion by means of his lectures and media appearances. However, it is hard to identify this popular, simplified and exaggerated message as the main conclusion of the study. Let us focus on pure science itself, on the research and its results. It is additionally justified by the fact that Blum's criticism is also aimed at the research itself, not the story created on the basis of it.

The SPE was deeply immersed in the prison context and its purpose was to show the pathology of such system and the need for reform. This specific, narrow context is overlooked by the critics, what is more - it is overlooked almost by everyone. Therefore, the key question is: is it Zimbardo and his research that is accused of trivialisation and justification of evil, or is it the story about the research? In Blum's criticism, the boundaries between these are blurred.

There are two more problems with the argument that 'the SPE trivialises and justifies evil'. Even if the simple and general conclusion that 'evil is induced by the situation' can be drawn from Zimbardo's study, one cannot hold him accountable for the sentence: 'and therefore people are not responsible for their actions'. It just does not follow. Empirical statements (about what is) do not imply moral statements (what should be? What is good?), so the author of a scientific discovery should not become automatically responsible for moral recommendations and interpretations.

It seems honest to hold somebody accountable for a something that they openly, personally expressed, and not for the interpretation of their views which was given by somebody else. Zimbardo himself strongly disagrees with the idea that people are not responsible for their deeds (Zimbardo, 2018). His experiment was supposed to fight the extreme view that people's behaviours originate only within themselves - because of their permanent characteristics. He wanted to mitigate this stance rather than replace in with another extremity: 'people's behaviours are only determined by the situation' (Zimbardo, Haney, Banks, 1973). Acknowledgement of individual differences can be found in the original records on the experiment and Zimbardo's response to criticism. The author of the SPE describes himself as an 'interactionist', that is a supporter of the view that human behaviour results from the combination of circumstances and predispositions.

The last problem with the accusation that 'the SPE misled the humanity on the question of evil' stems from misunderstanding science. Namely, a single experiment does not prove anything. Anything at all. If the experiment had been carried out properly, it is no evidence that human evil is induced by the situation. If it had been carried out poorly, 
it is no evidence that evil is not induced by the situation. All the more so, it does not prove that evil comes from within. This is simply not how science works, and both the supporters and opponents of the SPE should bear this in mind. Scientific evidence is credible when multiple studies carried out by various teams in various ways and in various contexts indicate a similar pattern. The battle about credibility of one piece of research cannot be the battle about the final truth, especially such a generalised one.

\section{ZIMBARDO DEFENDED?}

We have reviewed the basic arguments of the latest SPE criticism - there is a grain of truth in them, but on the whole, they seem rather far-fetched. Thus, is the Prison Experiment defended? Definitely not.

\section{SPE is a poor scientific experiment. Actually, it is not even an experiment from scientific point of view - even the research team in their original article conspicuously uses the word 'demonstration'}

Let us start from the obvious methodological criticism - the SPE is tragically undefined. Neither the dependent and independent variables, nor hypotheses or theoretical frameworks were defined. There is no control group either, so we do not know to whom or to what the participants' behaviour should be compared. With our current standards, a study with such mistakes could make you fail a methodology class.

Methodological criticism is nothing new - it is not true that throughout the years the scientific community indiscriminately accepted the SPE as a prominent piece of research. A thorough methodological criticism was published in a peer-reviewed scientific journal in 1975 (Banuazizi, Movahedi 1975). Critical voices had also been raised earlier in influential popular science sources (cf. e.g. article in Psychology Today from 2013). In order to see the shortcomings of the research for oneself, it is enough to read an academic methodology textbook and see what are the requirements for a psychological experiment (e.g. Brzeziński, 1996).

However, Ben Blum adds something interesting to the common criticism - not all of his theses are exaggerated. Firstly, he presents convincing doubts about whether the participants could quit the experiment on demand. Secondly, he outlines the scope of the team's ideological motivation and the lack of mechanisms that could prevent the team from influencing the results with their expectations.

As I wrote earlier, I doubt if Blum's arguments prove that the guards were induced to aggression. There is no strong evidence that would support it. But there is plenty of evidence that the researchers let their expectations shape the results. Zimbardo and his team wanted to lead to a prison reform because they were deeply convinced that existing system elicited the worst features of a human being and was not serving the societal goals. As intended, the results were used as arguments in a political discussion (cf. Blum, 2018).

In such conditions, the researchers intervened to a remarkable extent. The research team which aims to get specific results and believes in the importance of their own social mission, is directly involved in shaping of the experimental situation in hand. What is more, they even convince the participants - the guards - to their ideas (cf. e.g. Reicher, Haslam, Van Bavel, 2018). As if the experiment was supposed to 'demonstrate that...' rather than 'answer the question if...'. It is a fundamentally unscientific approach.

It can be proved not only by the recorded conversation between Jaffe and the guard, but also by his diary, a statement by David Eschelman (in: Blum, 2018) and commonly known facts - the researchers were directly involved in carrying out the research and during the initial guard's send-off they explicitly suggested how the roles should be played.

Another interesting and justified element of Blum's criticism is the question of the prisoners' voluntary participation. Were they allowed to quit the experiment? Did they know how to do it? The aforementioned Douglas Gordi claims that he faked a nervous breakdown so that he could have access to his textbooks. He also claims that he was not allowed to leave. Another prisoner, Richard Yacco, confirms this version. Zimbardo initially declined these allegations and explained that a special password had been settled in case any of the prisoners wanted to quit; however, he did not provide any evidence. There is no trace of such agreement in the documents and Zimbardo completely ignores this element in his response to Blum's criticism. 
We can also find some circumstantial evidence that Gordi and Yacco might be telling the truth. For example, in the original article, the authors are surprised that some prisoners became so engrossed in their roles that they asked their lawyers to negotiate their 'release on bail' (Haney, Banks, Zimbardo, 1973). Whereas psychologist Ervin Staub in his review of Zimbardo's book The Lucifer Effect writes: 'the prisoners' psychological state seemed affected by the belief that, contrary to the original agreement, they could not choose to get out of this prison until the end of two weeks (Staub, 2007).

Perhaps the prisoners talked about getting out of the prison as a part of their role, and the prison staff responded that there was no such possibility, also as a part of their role? Maybe neither of these groups knew where was the boundary between authenticity and an actual role-playing game, because from the very beginning it was not clear how to recall this authenticity. How to convey: 'I am now talking as me, not as the prisoner'? There is evidence confirming that this was the case, and two conclusions follow. Firstly, the experiment was even worse from the ethical point of view than we thought. Secondly, the participants were not derealised at all - they were really locked in prison for some time.

\section{THE STANFORD PRISON EXPERIMENT AND PSYCHOLOGY}

The SPE has never been a study of great importance in science. It did not lay foundation for any new current, did not constitute any breakthrough in the knowledge on human nature and it is not exceptionally respected among academics. It is worth noticing that Philip Zimbardo did not build his career upon it - he became more recognizable to wider audiences. Before he carried out the SPE, he had already been a reputable researcher, an author of a valued textbook and a popular science programme as well as a full-time lecturer at a prestigious university. Later on, he tackled a wide range of other issues and his most often cited works are those regarding the perception of time and prosocial behaviour among children (Scopus citation database). Thus, the criticism of the SPE did not devastate Philip Zimbardo's output or scientific credibility. It is worth to bear this in mind.

The SPE is rather an educational story, or even a parable - it is supposed to shock and warn us. It would make sense if its conclusions were proved elsewhere. In that case we could accept the endeavour, but as a demonstration and not as evidence. I do not dare to state unequivocally if people in total institutions do fall into mechanisms indicated by the SPE. All the more so, because for ethical reasons the experiment has been replicated only once (Lovibond, Adams, 1979). On the other hand, we know that social psychology found ample evidence that we often underestimate the influence of circumstances on our behaviour and that we declare moral behaviour more often than we practice it (cf. e.g. Grzyb, 2017).

\section{SUMMARY}

Ben Blum's article "The lifespan of a lie" is an exaggerated and biased criticism of an exaggerated and biased study, and the whole issue is a great exercise in critical thinking for the readers. Despite the faults in Zimbardo's research, we should still rationally asses the criticism; evaluation of the experiment and its original conclusions is not the same as evaluation of common, simplified interpretations.

It is very easy to become passionate about debunking authorities or steadily defending them. As conscious recipients of knowledge, let us avoid the favoured, quick 'for or against' assessments, examine the quality of arguments and accept the complex image of reality. Blum falls into the same trap as the Prison Experiment - a chase after an unequivocal conclusion, at the same time ignoring those fragments of reality which could undermine it and highlighting those which confirm it.

\section{Both the criticism and the research went in a wrong direction - towards the land of simplifying and sensationalizing science in the academic discourse.}

Zimbardo and the critics got on this ride voluntarily and followed its rules: conclusions must be big and ground-breaking. Evidence - unequivocal. The truth must be finally disclosed and it must stand in absolute contrast to what we knew before ('this film will completely change everything you know about...'). One could also use villains and noble knights in a story like this. In the scientific version, both roles can be played by ideas, theories or competing researchers. 
Maybe the book by Thibault le Texier and the upcoming documentary based on the work will shed new light on the SPE and give us a clearer picture, but before these works are released in English, it is hard to judge for most readers. Stories about evidence are not evidence. We should learn this lesson in respect to SPE and pretty much everything else.

\section{REFERENCES:}

- Banuazizi, A., Movahedi, S. (1975). Interpersonal dynamics in a simulated prison: A methodological analysis. American Psychologist, 30(2), 152-160. https://doi.org/10.1037/h0076835

- Bhattacharjee, Y. (2013). Diederik Stapel's Audacious Academic Fraud. [online] Nytimes.com. Retrieved from: https://www.nytimes.com

- Blum, B. (2017). Ranger games: A story of soldiers, family, and an inexplicable crime. New York: Doubleday.

- Blum, B. (2018, July 6). The Lifespan of a Lie. Retrieved from Medium website: https://medium.com

- Brzeziński, J. (2012). Metodologia badań psychologicznych [eng. Methodology of psychological research]. Warsaw: Wydawnictwo Naukowe PWN.

- Festinger, L. (1980). Looking backward. Retrospections on social psychology, 236-254.

- Grzyb, T. (2017). Eksperyment terenowy w psychologii społecznej: Metodologia, etyka, praktyka. [eng. Field experiment in psychology: methodology, ethics and practice] Warsaw: Wydawnictwo Naukowe PWN.

- Haney, C., Banks, C., Zimbardo, P. (1973). Study of prisoners and guards in a simulated prison. Naval research reviews, 26(9), 1-17.

- Klebaniuk, J. (2012). Profesor Stapel on dope. On the beautifying of social psychology. Psychologia społeczna, 7(3), 213-217.

- Kousta, S. (2017). Cognitive science: Flawed reasoning. Nature Human Behaviour, 1, 0149.

- Le Texier, T. (2018). Histoire d'un mensonge: enquête sur l'expérience de Stanford. Paris: La Découverte.

- Lilienfeld, S. O., Lynn, S. J., Ruscio, J., Beyerstein, B. L. (2011). 50 great myths of popular psychology: Shattering widespread misconceptions about human behavior. John Wiley Sons.

- Lovibond, S. H., Adams, W. G. (1979). The effects of three experimental prison environments on the behaviour of non-convict volunteer subjects. Australian Psychologist, 14(3), 273-287.

- Reicher, S., Haslam, S. A., Van Bavel, J. J. (2018). Time to change the story. The Psychologist, 31(8), 2-3. Retrieved from: https://thepsychologist.bps.org.uk

- Staub, E. (2007). Review of The Lucifer Effect: Understanding How Good People Turn Evil by Philip Zimbardo. PsycCRITIQUES: American Psychological Association Review of Books, 52.

- Weaver, K., Garcia, S. M., Schwarz, N., i Miller, D. T. (2007). Inferring the popularity of an opinion from its familiarity: A repetitive voice can sound like a chorus. Journal of Personality and Social Psychology, 92(5), 821-833. https://doi.org/10.1037/0022-3514.92.5.821

- Witkowski, T. (2018). Lucyfer, którego wymyślił Zimbardo. O konsekwencjach stanfordzkiego eksperymentu więziennego i skandalu, którego stał się obiektem. [emg. Lucifer by Zimbardo’s design. On consequences of Stanford Prison Experiment and the following scandal] [online] W obronie rozumu. Retrieved from: https://tomwitkow.wordpress.com

- Zimbardo, P. (2018). Philip Zimbardo's Response to Recent Criticisms of the Stanford Prison Experiment. [online] Stanford Prison Experiment. Retrieved from : http://www.prisonexp.org/response/

- Zimbardo, P. G. (2006). On rethinking the psychology of tyranny: The BBC prison study. British Journal of Social Psychology, 45(1), 47-53. https://doi.org/10.1348/014466605X81720

- Zimbardo, P., Haney, C., Banks, W. C. (1973). A Pirandellian prison. New York Times Magazine, 8, $38 \mathrm{ff}$.

\section{LEARN MORE:}

- https://skeptoid.com/episodes/4102

- https://thepsychologist.bps.org.uk/time-change-story/

- https://www.livescience.com/62832-stanford-prison-experiment-flawed.html

- https://thesixfifty.com/was-the-stanford-prison-experiment-a-sham-a-q-a-with-the-writer-who-exposed-thecelebrated-study-17e5ba0eedef 
- https://www.vox.com/2018/6/13/17449118/stanford-prison-experiment-fraud-psychology-replication/

- https://www.vox.com/science-and-health/2018/6/14/17464516/stanford-prison-experiment-audio

- http://skepchick.org/2018/06/stanford-prison-experiment-lie/ 